\title{
DPFC Performance with the Comparison of PI and ANN Controller
}

\author{
D. Narasimha Rao ${ }^{1}$, T. Surendra ${ }^{2}$, S. Tara Kalyani ${ }^{2}$ \\ ${ }^{1}$ Department of Electrical and Electronics, K L University Guntur, India \\ ${ }^{2}$ Department of Electrical and Electronics, JNTU Hyderabad, India
}

\begin{tabular}{l} 
Article Info \\
\hline Article history: \\
Received Jun 9, 2016 \\
Revised Aug 19, 2016 \\
Accepted Sep 4, 2016
\end{tabular}

Keyword:

ANN

Current control

DPFC

FACTS

PFC

Symmetrical component

UPFC

VSC

\begin{abstract}
Modern power systems demand the active control of power flow and for this purpose Power flow controlling devices (PFCDs) are required. Distributed FACTS Controller (DPFC) is a part of FACTS family. DPFC offers equal control ability same as UPFC, comprising the adjustment of the internal angle of the machine and bus voltage includes line impedance. In addition to UPFC a new device evolved known as DPFC in which common DC link is eliminated that enables the exclusive working between the two converters which are shunt and the series. The Distributed-FACTS (D- FACTS) idea is adopt in the series converter scheme. The replacement of the high rating three phase series converter with the multiple low rating single phase converters results in cost reduction and increases reliability greatly. The useful power transfer between the two converters which are shunt and series through common de link in UPFC where as in DPFC in this the required power is transferred in the transmission line with three times of natural fundamental frequency. Where as in the new device no need of large voltage separation between the line and PFC Device is no requirement of high voltage isolation between because D-FACTS converters which are 1-ब floating device with respect to the ground. Accordingly, In this paper we bring out the DPFC performance differences with different control techniques which are PI and Artificial Neural Network Controllers and bring with conclusion that ANN is a better control strategy compared to PI.
\end{abstract}

Copyright (C) 2016 Institute of Advanced Engineering and Science. All rights reserved.

\section{Corresponding Author:}

D. Narasimha Rao,

Departement of Electrical and Electronics Engineering,

K L University,

Guntur, India

Email: narasimharao@kluniversity.in

\section{INTRODUCTION}

The increasing reputation in using renewable energy sources make it possible to control a huge sum of energy that enables the energy plan for quick switch between the renewable energy sources and the standby power generation [1]. This demands the availability of stand-by power whenever renewable energy is unable to supply the load. Therefore the need for power flow scheme methods is increased. The system parameters like internal angle and voltage magnitude are adjusted in order to control the active power. The PFCD is a component that modifies system parameters to control the active power [2]. The UPFC is the most powerful PFCD, able to alter system parameters like bus impedance, internal angle, and bus voltage. The operating principle of device UPFC is executed by the series converter casting a voltage, with specified phase angle, magnitude, in line with the power line [3]. The DPFC resembles the UPFC in independent adjustment of the line impedance, same control capability, internal angle and the bus voltage. In DPFC the DC voltage fluctuations are eliminated which connects the shunt and series converters back to back in UPFC [4]. 
Figure 1 shows configuration of DPFC consisting of parallel and series connected converters as in case of UPFC. Each converter within the DPFC is independent having its own DC capacitor that provides required DC voltage. Other than parallel and series controllers, DPFC needs an frequency eliminator connected parallel to one side of line and on other side of line there is a Y- $\Delta$ transformer.

There are two major advantages of DPFC compared to UPFC:

1. Low voltage isolation and the series converter's low component rating causes low cost and

2. The redundancy of the series converters causes high reliability

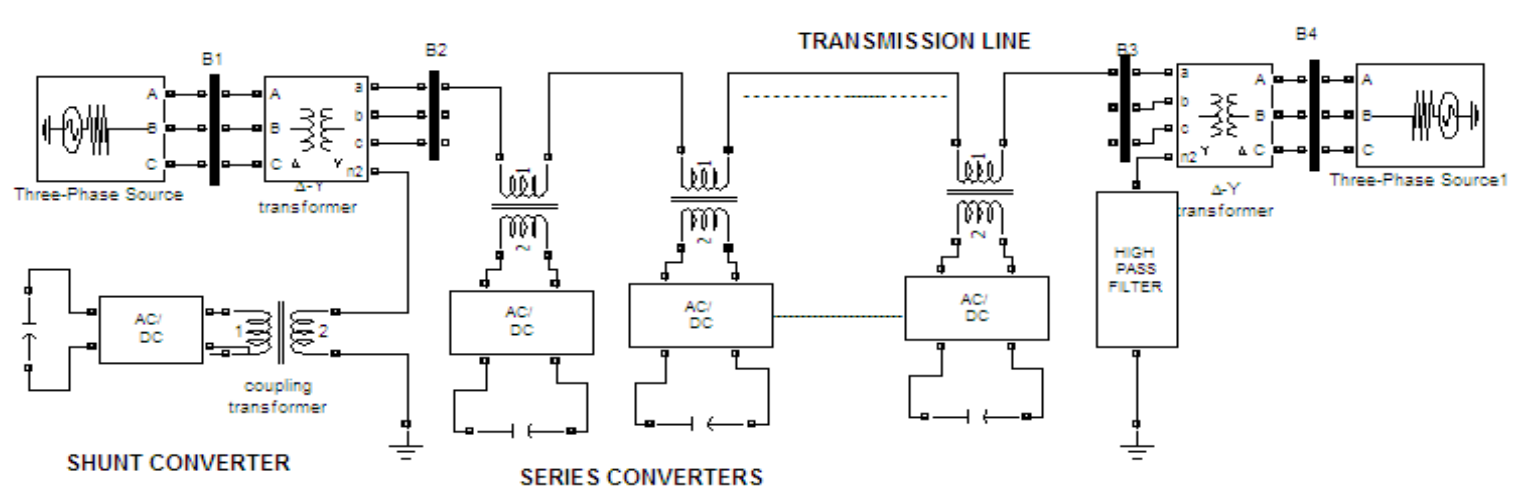

Figure 1. Distributed power flow controller

\section{DPFC PRINCIPLE}

The transmission line is the common connection between the AC supply to the parallel and the series controllers through which real power is transferred. In Fourier analysis the non sinusoidal current and voltage is given by the addition of sinusoidal functions in different frequencies with different amplitudes [5].

The active power that results from non sinusoidal current and voltage is defined as the product of voltage and current. The real power can be expressed as in equation (1)

$$
P=\sum_{i=1}^{\infty} V_{i} I_{i} \cos \emptyset_{i}
$$

where $I i=$ current

$\mathrm{V} i=$ voltage

$i^{\text {th }}=$ harmonic frequency

$\emptyset_{i}=$ phase angle between the harmonic currents and voltages.

From the above equation it is observed at different harmonic frequencies of active power is insulated from each other and the real power at other harmonic frequency is not affected by the voltage or current. The real power is independent at different frequencies; this converter without AC power source generating active power at one harmonic frequency to absorb the same power that other component frequency [6],[7]. Following the same approach in DPFC, active power can be absorbed by the parallel converter from source at supply frequency and inserted in to the system at other frequency component. This harmonic component of current flows through the power line. Based on the quantity of real power required by the system at the fundamental frequency, the voltage is generated by the DPFC series converters at the harmonic frequency thus absorbing the power from the line send by the other converter. Here a lossless converter is assumed, so that active power generated at fundamental component frequency and the power absorbed from the harmonic frequency are assumed as equal. The high-pass filter of the DPFC allows the passage of the fundamental components, blocking the harmonic frequency components, by that showing the harmonic components to have a return path. The harmonic current is circulated through high-pass filters, series and parallel converters and the ground. For the exchange of the real power in the DPFC the third harmonic frequency component is identified due to its unique character of the frequency 3rd harmonic components. In a 3- $Q$ system, the fundamental and 3rd multiple component combined inject current into the grid." The zero-sequence harmonics is not allowed by Y-transformers, which are useful to mitigate reduce voltage level deficiency in power system. Therefore, there is no requirement of excess filter to rest of the network for mitigating the harmonic leakage [8],[9]. 


\subsection{DPFC control principle}

Figure 2 shows the three types of controllers that control the multiple converters; they are main control, series control and shunt control. The parameters of series and parallel control are maintained by themselves, they are also called as local controllers. At the system level the central control controls the DPFC functions.

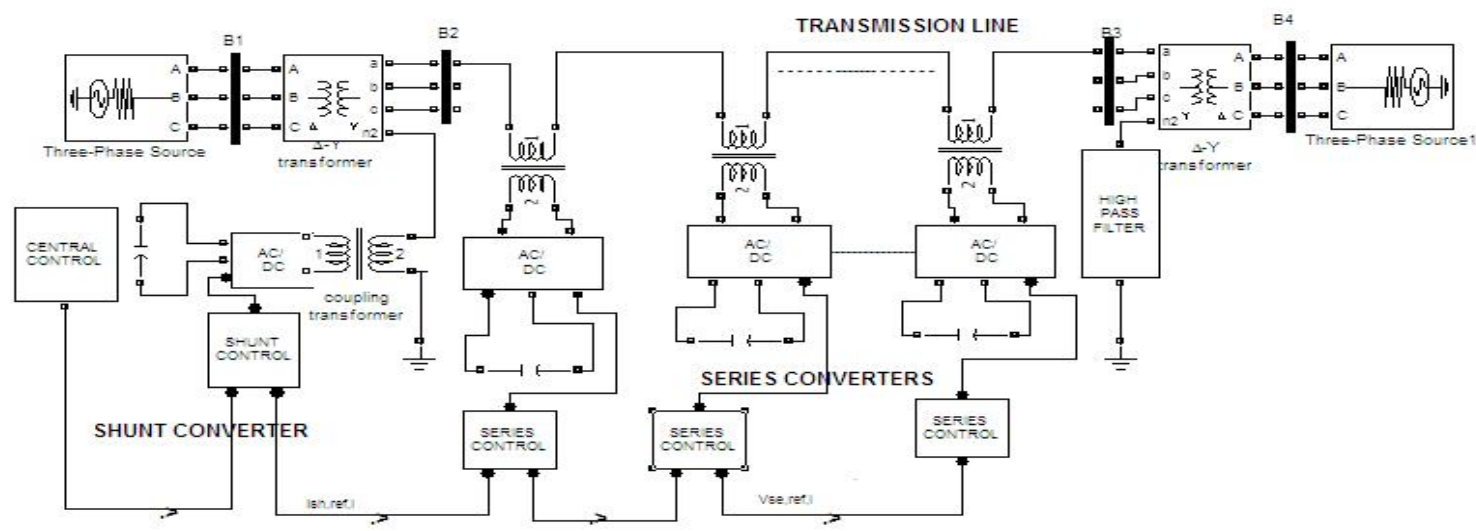

Figure 2. Block Diagram of DPFC with Controller

\subsubsection{Central Control}

The foremost function of the main control commonly known as central controller is to generate reference signals for controlled converters of the DPFC. These are generated at the system frequency. The central control gives reference signal of current and voltages for both the controllers in accordance with the system requirement [10]. At the system level, the central control is dependent on the functional operation of the DPFC, they are damp out power oscillations at low frequency, power-flow control and asymmetrical components balancing.

\subsubsection{Series Control}

Series control is present in all the single phase converter circuits. The controller is to fix the capacitor DC voltage of converter with the help of 3rd harmonic voltage or currents. It injects voltage at supply frequency approved by the main control [5]. In DPFC series converter control, the major control loop is the third harmonic frequency control. For DC voltage control phasor control principle is applied [6],[7].

\subsubsection{Shunt Control}

It injects a fixed power which combination of fundamental and third harmonic component current into transmission line in order to transmit the real power for series converters is the main objective of shunt control. At the fundamental frequency of the 3rd harmonic current and bus voltage are locked. The motto of shunt converter is to exchange required reactive power to grid and also maintaining fixed DC capacitor voltage.

\section{CONTROLLER DESIGN}

\subsection{PI Controller design}

The transfer function for PI controller is defined as:

$$
H_{P I}(s)=K_{P}+\frac{K_{I}}{s}
$$

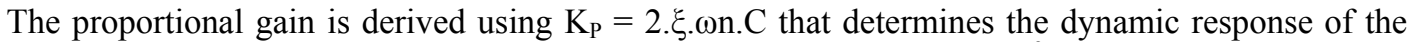
DC-side voltage control. Similarly, the integral gain is derived using $K_{I}=\mathrm{C}_{\mathrm{n}}{ }^{2}$ calculating settling time [11],[12]. 


\subsection{ANN controller of DC voltage}

ANN is part of the family of statistical learning methods inspired by biological nervous system and are used to estimate and approximate functions that depends only on a large number of inputs.

ANN is an interconnection of neurons which send messages to each other. The connections have numerical weights that can be tuned based on experience This paper draws attention on the multi layer feed forward ANN which that of the non linear multivariable function representation. The ANN is used for the mapping between the difference of reference DC and Changed Value of DC on DC side of series converter for proper operating conduction and optimal controller parameter [13],[14]

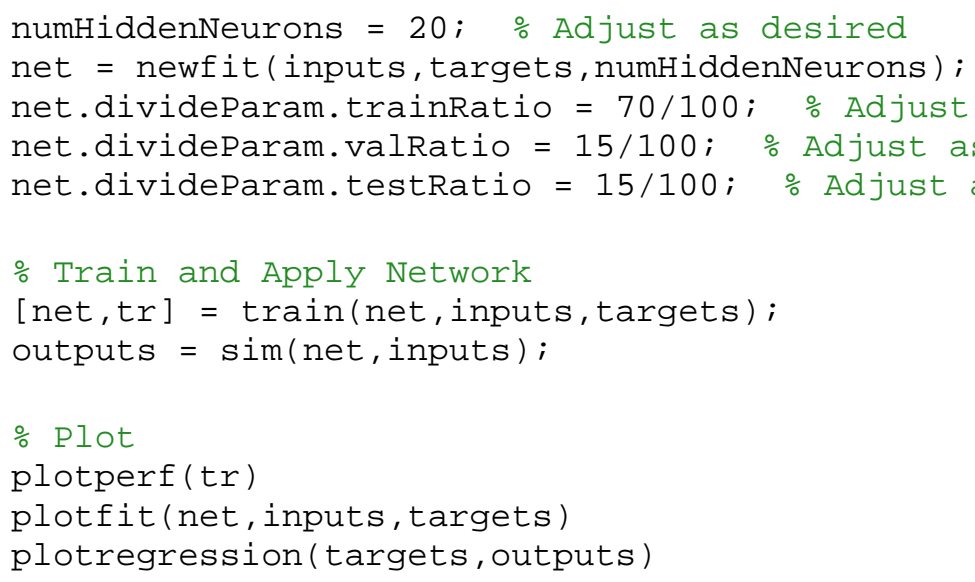

Table 1. Measured Values of converter

\begin{tabular}{clc}
\hline Symbol & \multicolumn{1}{c}{ Description } & Value \\
\hline $\mathrm{V}_{\text {sh,max }}$ & Maximum voltage by shunt converter & 50 Volt \\
$\mathrm{I}_{\text {sh,max }}$ & Maximum current by shunt converter & $10 \mathrm{Amp}$ \\
$\mathrm{V}_{\text {,dc }}$ & DC source Voltage & $20 \mathrm{Volt}$ \\
$\mathrm{I}_{\mathrm{sh}, \text { ref,3 }}$ & Harmonic reference current value by parallel & $3 \mathrm{Amp}$ \\
$\mathrm{f}_{\mathrm{sw}}$ & parallel and Series Converter Switching frequency & $6 \mathrm{kHz}$ \\
$\mathrm{V}_{\mathrm{se}, \max }$ & Series Converter Maximum Voltages & $7 \mathrm{Volt}$ \\
$\mathrm{I}_{\mathrm{se}, \max }$ & Series Converter Injected Maximum Current & $15 \mathrm{Amp}$ \\
\hline
\end{tabular}

Table 2. Model parameters

\begin{tabular}{clc}
\hline parameter & \multicolumn{1}{c}{ Abbreviation } & Quantity \\
\hline $\mathrm{V}_{\mathrm{s}}$ & Voltage at sending end bus & $220 \mathrm{~V}$ \\
$\mathrm{~V}_{\mathrm{r}}$ & Voltage at receiving end bus & $220 \mathrm{~V}$ \\
$\theta$ & Angle between the two buses & $1^{\circ}$ \\
$\mathrm{L}$ & Inductance of a line & $6 \mathrm{mH}$ \\
\hline
\end{tabular}

\section{SIMULATION RESULTS}

To simulate the ANN or PI controlled DPFC, a model in Mat lab/Simulink is developed. Simulation workout is taken out to check the working performance of DPFC in a transmission system. A simulation is carried out by a simple two bus system. Energy transfer between the two buses is obtained by giving a phase difference with in the two buses. DPFC consists of one parallel converter and $61-Q$ series controllers. The parallel facts device is a $1-Q$ converter placed between neutral point of $\Delta-Y$ transformer and neutral, and is given by constant DC supply. Transmission system with a voltage of $380 \mathrm{~V}$ and $50 \mathrm{~Hz}$ are considered for simulation.

\subsection{DPFC using PI}

In Figure 4 PI controller injects voltage to series converter, voltages and currents at the Deltatransformer are shown in Figure 8. Figure 5 and 6 show the fundamental components of series injected voltage and line current respectively. In Figure 4 injected voltage through controller is of PWM generated shape consisting of two frequency components. 
Performance of the controller is analyzed by the Fast Fourier Transform FFT shown in Figure 9 to 11 fundamental voltage injected due to PI through series converter is also analyzed by using a tool FFT. The performance of converter voltage is analyzed by a tool FFT shown in Figure 9 to 11 this tool actually available in mat lab used to check the value of fundamental component of voltage injected by the converters.

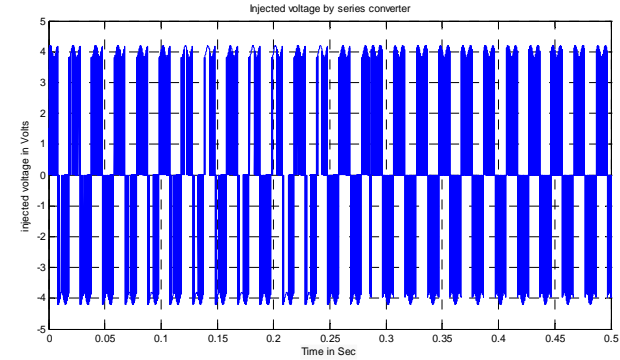

Figure 4. Series converter Injected voltage

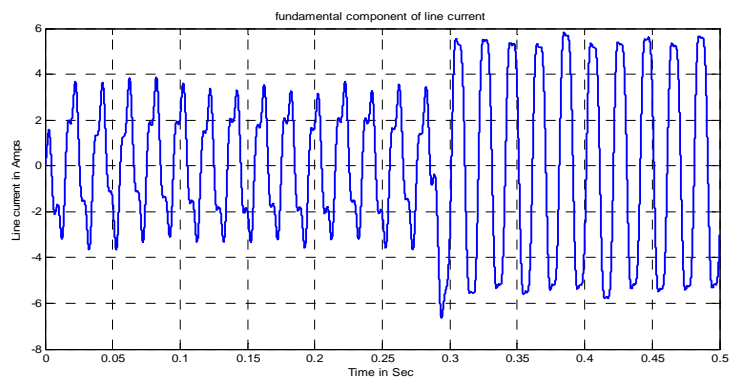

Figure 6. Fundamental component of line current

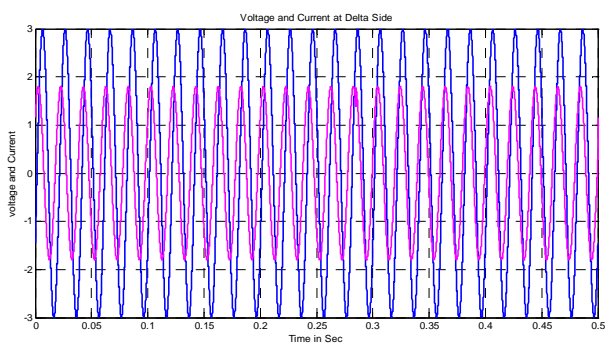

Figure 8. Delta side transformer currents and voltages

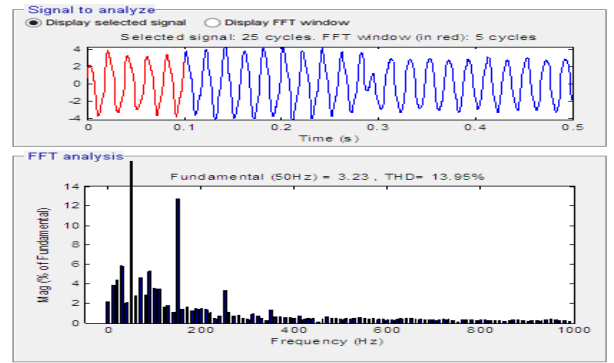

Figure 10. THD analysis - Voltage

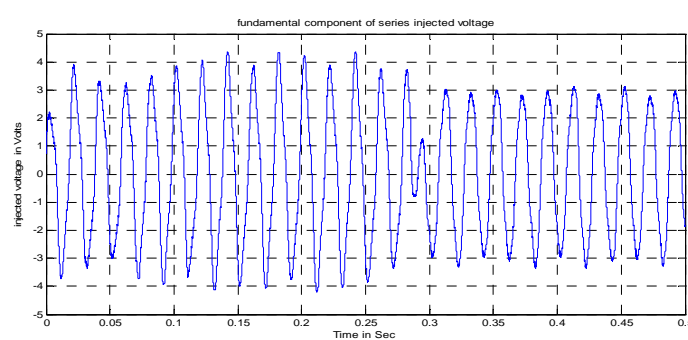

Figure 5. Fundamental component of series injected Voltage

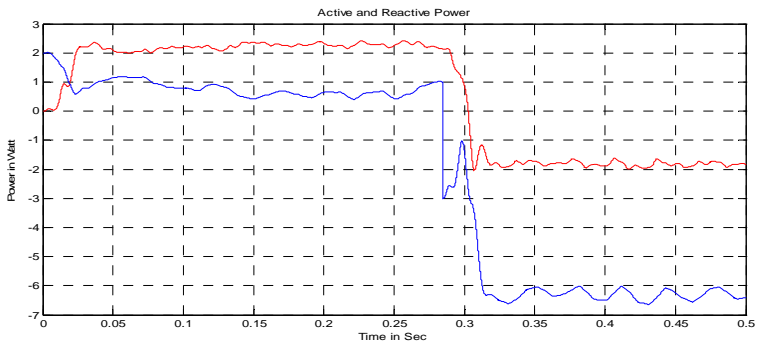

Figure 7. Active and Reactive power

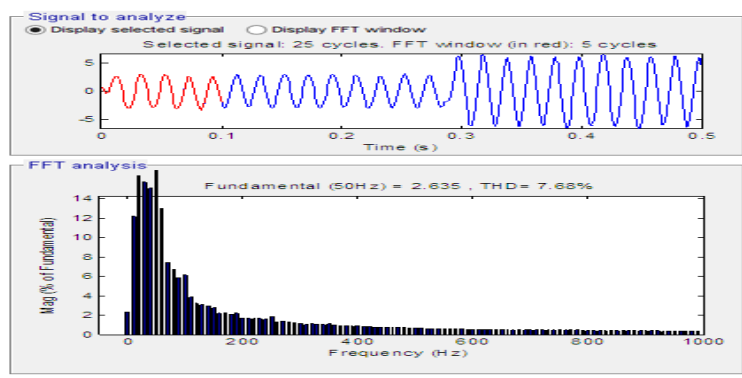

Figure 9. THD analysis - IREC

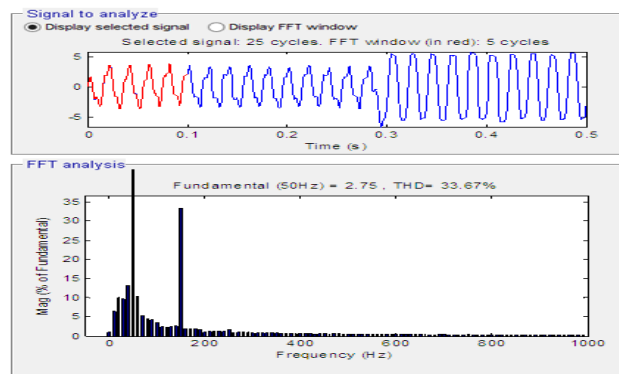

Figure 11. THD analysis - Current 


\subsection{DPFC using ANN}

In Figure 12 ANN controller injects voltage to series converter, voltages and currents at the Deltatransformer are shown in Figure 15. Figure 13 and 14 show the fundamental components of series injected voltage and line current respectively. In Figure 12 injected voltages through controller is of PWM generated shape consisting of two frequency components. Performance of the controller is analyzed by the Fast Fourier Transform FFT shown in Figure 16 to 18 fundamental voltage injected due to ANN through series converter is also analyzed by using a tool FFT. Simulation results show that the ANN controller offers better performances than the PI, as shown in Table 3.

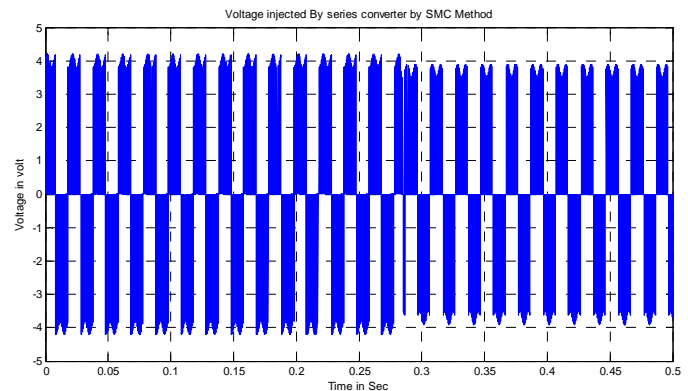

Figure 12. Voltage injected by series controller

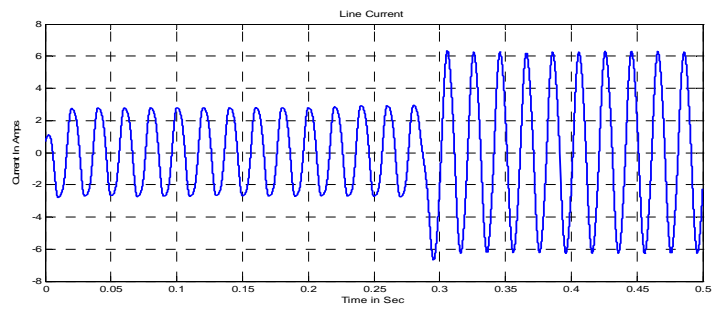

Figure 14. Line current

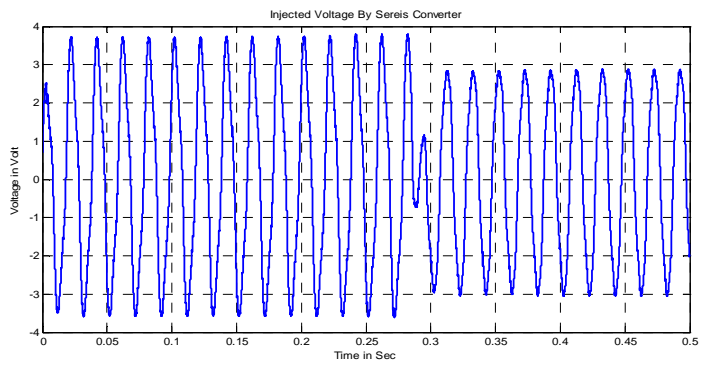

Figure 13. Injected voltage by series converter

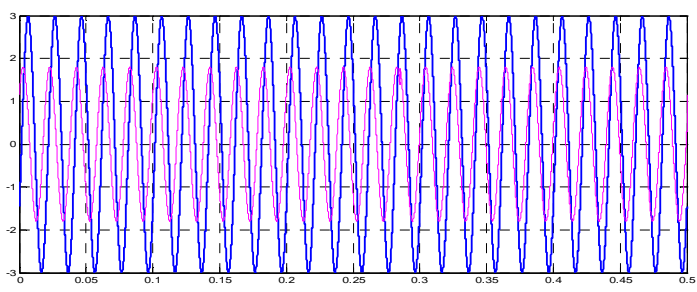

Figure 15. Voltage and current at the delta side

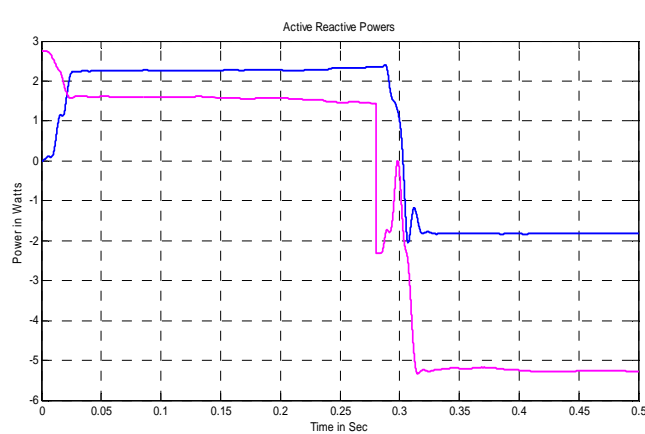

Figure 16. Real and Reactive power

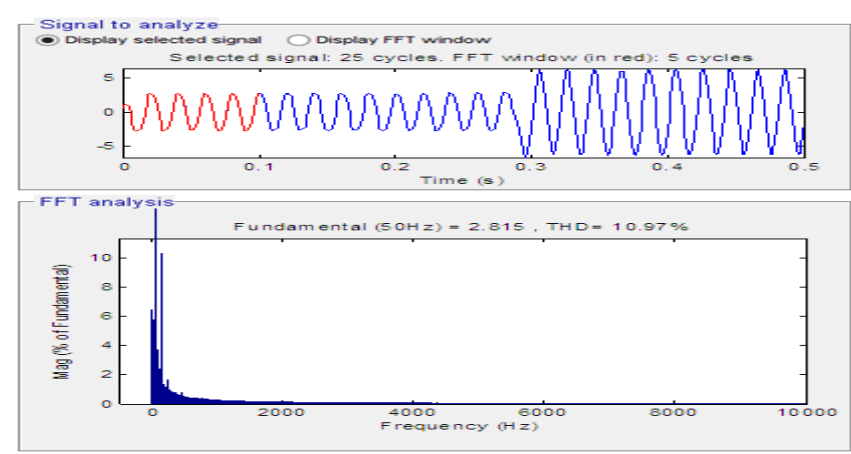

Figure 17. THD analysis-Voltage 


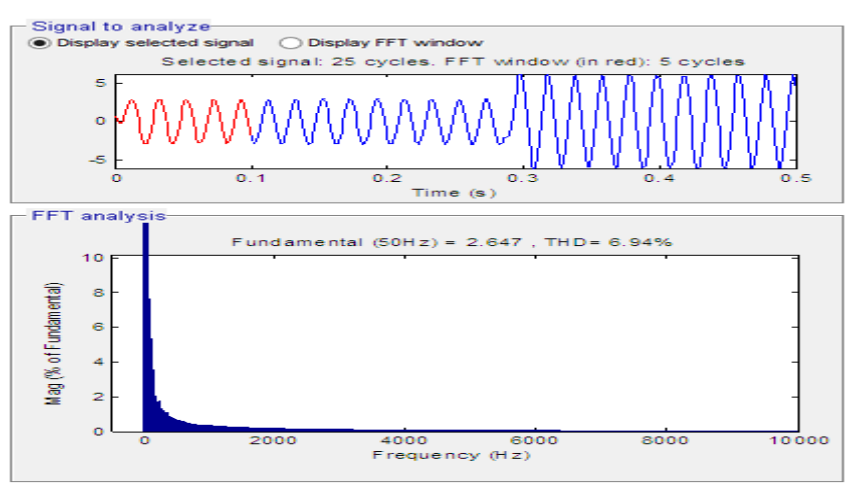

Figure 18. THD analysis- IREC

Table 3. Performance comparison

\begin{tabular}{lcc}
\hline & PI & ANN \\
\hline Series inject Voltage (Ist & $78.9 \%$ & $78 \%$ \\
And $3^{\text {rd }}$ ) Component & & \\
Fundamental injected & $14 \%$ & $13 \%$ \\
voltage & $12.96 \%$ & $11 \%$ \\
Line Current & $7.68 \%$ & $7.1 \%$ \\
Current at receving end & & \\
\hline
\end{tabular}

\section{CONCLUSION}

Two PI and ANN control strategies with DPFC were consider in this work. These controllers are used in order to continuous change based on condition the DC voltage of the series converter and enhancing the dynamical performances. Several conditions is been taken in account in order to show that THD in series injected voltage. The simulation is done using MATLAB/SIMULINK. The results obtained by simulation show that the ANN controller offers better performances than the PI.

\section{REFERENCES}

[1] Y. H. Song and A. Johns, "Flexible ac Transmission Systems (FACTS)," IEE Power and Energy Series, vol. 30. London, U.K., Institution of Electrical Engineers, 1999.

[2] N. G. Hingorani and L. Gyugyi, "Understanding FACTS: Concepts and Technology of Flexible AC Transmission Systems," New York, IEEE Press, 2000.

[3] L. Gyugyi, et al., "The unified power flowcontroller:Anewapproach to power transmission control," IEEE Trans. Power Del., vol/issue: 10(2), pp. 1085-1097, 1995.

[4] D. N. Rao and V. Saritha, "Power System Oscillation Damping Using New Facts Device," IJECE, vol/issue: 5(2), 2015.

[5] M. D. Deepak, et al., "A distributed static series compensator system for realizing active power flow control on existing power lines," IEEE Trans. Power Del., vol/issue: 22(1), pp. 642-649, 2007.

[6] A. A. Edris, "Proposed terms and definitions for flexible ac transmission system (facts)," IEEE Trans. Power Del., vol/issue: 12(4), pp. 1848-1853, 1997.

[7] K. K. Sen, "SSSC-static synchronous series compensator: Theory, modeling, and application," IEEE Trans. Power Del., vol/issue: 13(1), pp. 241-246, 1998.

[8] Y. Zhihui, et al., "Utilizing distributed power flow controller (dpfc) for power oscillation damping," in Proc. IEEE Power Energy Soc. Gen. Meet. (PES), pp. 1-5, 2009.

[9] Y. Zhihui, et al., "Dpfc control during shunt converter failure," in Proc. IEEE Energy Convers. Congr. Expo. (ECCE), pp. 2727-2732, 2009.

[10] D. Divan and H. Johal, "Distributed facts-A new concept for realizing grid power flow control," in Proc. IEEE 36th Power Electron. Spec. Conf. (PESC), pp. 8-14, 2005.

[11] Y. Sozer and D. A. Torrey, "Modeling and control of utility interactive inverters," IEEE Trans. Power Electron., vol/issue: 24(11), pp. 2475-2483, 2009.

[12] L. Huber, et al., "Review and stability analysis of pll-based interleaving control of $\mathrm{dcm} / \mathrm{ccm}$ boundary boost pfc converters," IEEE Trans. Power Electron., vol/issue: 24(8), pp. 1992-1999, 2009.

[13] M. Mohaddes, et al., "Steady state frequency response of statcom," IEEE Trans. Power Del., vol/issue: 16(1), pp. 18-23, 2001.

[14] D. K. Mishra, "Efficient algorithm for load forecasting in electrical power system using artificial neural network," International journal of latest research in science and technology, pp. 254-258. 


\section{BIOGRAPHIES OF AUTHORS}

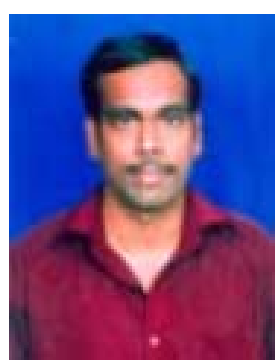

D.Narasimha Rao working as associate Professor in KLU University Guntur Completed B.Tech in EEE and Masters in Power Electronics and industrial Drives and Presently Pursuing PhD In JNTU Hyderabad and my research area are FACTS Controllers, Power Electronics

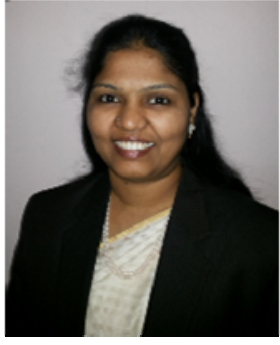

Dr T Surendra Received B.Tech in Electrical and Electronics Engineering. He received the Ph.D. degree from Jawaharlal Nehru technological university (JNTU) Hyderabad in 2008. He is currently a Director in vision Lighting and Energy India Pvt Limited and Visiting Professor in University.He has published/presented number of technical research papers in National \& International Journals. Her research interests include Facts Controllers, Power electronics industrial drives and Energy systems

Dr S.Tara Kalyani received the B.Eng. degree in Electrical and Electronics Engineering from Osmania University, Hyderabad in 1995. She received the Ph.D. degree from Jawaharlal Nehru technological university (JNTU) Hyderabad in 2008.she is currently a Professor \& Head in the Dept.of Electrical and Electronics Engineering from JNTU Hyderabad. She has published/presented number of technical research papers in National \& International Journals. Her research interests include Facts Controllers, Power electronics industrial drives and Energy systems 